\title{
Appropriate Technology
}

\section{Equipment for the gastroenterologist}

\section{JOHN NICHOLLS}

In Western countries gastroenterologists depend to a great extent on supporting services: radiology, biochemistry, haematology, microbiology, and histopathology. In the Third World, where these support services may be rudimentary or even non-existent, the gastroenterologist must learn to make full use of his own facilities and to extend his skills by undertaking some of the techniques that he would normally delegate to others.

\section{Basic needs}

Before consideration of the tools of the trade it is worth emphasising that a good history is always important, and as local interpretation of common terms such as indigestion, colic, and bellyache vary from country to country or even district to district it is a good idea to compile a glossary of local terms. One of the best ways to do this is to enlist the help of a locally trained community nurse. Her translating skills are likely to be invaluable and should be sought early, before misconceptions in the ability to acquire knowledge of a local dialect delude the patients (and the doctor) that the practitioner is fully conversant with the local vernacular.

Over the past few years Western doctors have been spoilt by ready access to disposable items, largely because of the high labour costs concerned in making such items reusable. Where labour is cheap, however, certain items such as mouth spatulas, rubber gloves, syringes, needles, and proctoscopes may have to be reused. The main disadvantage of reusable items is that there is a risk of transmitting infection including viral hepatitis if sterilisation is not adequate. In terms of cost, reusable items are usually cheaper in the long run.

Proctoscopes and sigmoidoscopes are the basic items of equipment, and I think that an interchangeable set with a fibre light source-for example, the Lloyd Davies pattern, supplied by Seward, UAC House, Blackfriars Road, London SE1 9UGis preferable to the newer disposable apparatus. To use these instruments effectively a good light is essential, and fibreoptic bundles are robust enough to withstand long use. The bulb for the light source may be obtained from a local photographic dealer. This source of light is much better and more reliable than that obtained from a battery or transformer. Although a good strong torch is adequate for proctoscopy in areas where the electricity supply is unreliable, it is inadequate for sigmoidoscopy, so in the long run the fibreoptic bundle is the best bet.

A glass Gabriel syringe and supply of reusable needles are further pieces of essential equipment. These enable the gastroenterologist to treat piles-a surprisingly common complaint in the Third World-in the outpatient department.

Good weighing scales-for example, the basic model supplied by Marsden, 388 Harrow Road, London W9-which also measure height are another useful item. Finally, a tape measure and pair of Holtain skin callipers are useful to assess malnutrition. It is a good idea to measure a range of normal people in the community to establish a rough estimate of local standards.

Hemel Hempstead General Hospital, Hertfordshire HP2 4AD JOHN NICHOLLS, FRCS, consultant surgeon

\section{Special equipment}

Many of the following items rely on electricity, and even if there is a fairly reliable mains supply it is advisable to have a small portable petrol driven generator.

A microscope is essential, and the gastroenterologist must learn to use this proficiently. It is advisable to have a microscope in or near the outpatient department so that rapid microscopy of specimens of stools for parasites and of urine for casts and cells may be carried out. The microscope should be capable of up to 400 times magnification. Those that are suitable for thisfor example, a Leitz microscope-usually operate with internal illumination only; thus it is advisable to keep a second microscope that is illuminated by natural light in case the electricity supply fails. The microscope may require to be tropicalised to prevent fungus growing on the lenses in humid environments. The same microscope may be used to examine blood samples to assess red cell morphology and for looking at thick films for malarial parasites. A supply of counting chambers and appropriate stains (Giemsa rather than Leishman) must, therefore, be supplied, and an oil immersion lens of 100 times magnification.

The inequality between Western and Third World countries is possibly nowhere more apparent than in the laboratory. Automated instruments and computers have little or no place in the Third World. ${ }^{1}$ I have compiled a brief guide to what equipment is needed and which investigations the gastroenterologist may expect (or arrange) to be obtained simply and cheaply:

(1) Refrigerator: for general purposes, and for keeping vaccines, reagents, etc.

(2) Microscope (as above).

(3) Simple colorimeter: this needs to be cheap, sturdy, and capable of operating trouble free in extremes of climate. With this, measurement of urea, bilirubin, alkaline phosphatase, calcium, and protein concentrations is possible.

(4) A local supply of chemistry systems: if these are not available the stick test strips (Miles-Ames) are preferable to prepacked chemistry systems.

(5) Flame photometer: this requires a gas supply in addition to electricity but is more robust than the ion selective electrode apparatus, which requires only electricity. It enables sodium and potassium concentrations to be measured.

From this list evidently the scope of laboratory investigations is necessarily restricted; investigation of complex metabolic problems is likely, therefore, to be beyond the means of the gastroenterologist in the Third World. The World Health Organisation has prepared a manual with detailed descriptions of essential tests for the primary hospital in the Third World. ${ }^{2}$

\section{Providing an endoscopy service}

In developed countries endoscopy is an essential part of gastroenterological practice, both in diagnosis and, increasingly, in treatment. But is this technology appropriate for the Third World? I believe that it is, and if the equipment is chosen carefully the gastroenterologist may provide an effective endoscopy service, even in a fairly primitive environment. Difficulties 
in funding the capital cost of an endoscopic service should be weighed against the possible savings in other departments-for example, the $x$ ray department and operating theatre. Maintenance of the endoscope and repair costs need to be kept to a minimum by careful handling (restricted to the expert user), scrupulous cleaning, and possibly some patient selection (a young alcoholic may destroy a fibre bundle with one bite). Another potential hazard of providing an endoscopy service is that of transmitting the hepatitis virus. In developing countries the reservoir of asymptomatic carriers may be high, and thus the risk is proportionately increased. It is, therefore, important to follow the guidelines on disinfection of endoscopes given by the endoscopy subcommittee of the British Society of Gastroenterology. ${ }^{3}$

Everyone will have experienced the frustration of attempting to use a particular piece of equipment only to find that the vital connector, plug, or fuse is not available. The frustration is likely to be heightened if it takes weeks to obtain the missing part. To avoid this the endoscopist must buy a comprehensive, adaptable, and interchangeable system of endoscopes. It is thus advisable to purchase equipment produced by one company alone, despite the claims by manufacturers of the individual uniqueness of their product. The two companies that deal with the most comprehensive range of endoscopic equipment in the United Kingdom are KeyMed (KeyMed House, Stock Road, Southend-on-Sea, Essex), who supply the Olympus range, and Pyser (102 College Road, Harrow HA1 1BQ), who supply the Fuji range. I suggest that an end viewing gastroduodenoscope and a colonoscope are purchased as the two basic pieces of equipment, together with biopsy facilities and possibly snares. (The snares may require modification to be used with a standard diathermy apparatus.) Refinements of these endoscopes for investigating the pancreatic and biliary trees are not usually an advantage because treatment is likely to be so difficult that it cannot be undertaken readily in a Third World hospital.

Providing an endoscopy service has the obvious advantage that the endoscopist will not have to rely on a radiological colleague for barium examination. Provided that the gastroenterologist becomes proficient at using the microscope he may manage without a specialist in pathology, for many pathological specimens may be identified by their macroscopic appearance alone. Biopsy specimens are suitably small to be sent away by post, so it may be useful to establish a link with a laboratory in the United Kingdom that is prepared to report on the histological appearance of such specimens whenever necessary.

\section{Additional items}

Various needles may be used for percutaneous biopsy: Tru-cut or Menghini needles are available from the American Hospital Supply, Station Road, Didcot, Oxfordshire. These needles, however, are expensive because they are disposable, and the pathological specimen that is obtained is small and will almost certainly have to be sent away to a laboratory that is familiar with handling cores of tissue. Pathological specimens of tissue may, of course, be obtained at laparoscopy, but this technique demands experience and you also need expensive apparatus and a supply of carbon dioxide gas. As a rule, open biopsy at operation is more satisfactory, and it gives the surgeon the opportunity to assess the full extent of the disease and, if possible, to treat.

Special therapeutic equipment will not necessarily differ from that used in Western countries, although certain adaptations may be required to meet local needs. Stoma care equipment does not need modification as the bags are designed to cope with a wide range of circumstances. Companies with a comprehensive range of products are: Abbot Laboratories Ltd, Queensborough, Kent; Colopast Ltd, Bridge House, Orchard Lane, Huntingdon, Cambridge; Downs Surgical, Church Path, Mitcham, Surrey; Squibb Surgicare Ltd, Squibb House, 141 Staines Road, Hounslow, Middlesex.
It is always important to find out what the home conditions of the patient are like: lack of a good water supply or an adequate drainage system leads to obvious problems in terms of maintaining personal hygiene and disposing of plastic materials. It is equally important to be aware that local customs may result in a patient with a stoma becoming ostracised. These factors should influence your decision to operate-for example, on a patient with abdominal cancer-and leave the patient with a colostomy or ileostomy. Remember that heroic attempts to remove cancer are not greeted with the same enthusiasm as in the West. An international organisation of stomatherapists (World Council of Enterostomal Therapists, 926 East Tallmadge Avenue, Suite C, Akron, Ohio 44310, USA) has been formed to help with stoma problems world wide.

Parenteral nutrition is seldom practicable. Even if it were possible to set up and satisfactorily maintain a long intravenous line the preparation of suitable solutions for infusion, ensuring their sterility, and monitoring their effect will demand too much in terms of time and resources. Although malnutrition is a common problem, it may, in most cases, be treated by oral supplements or by feeding the patient through a fine bore feeding catheter. A range of these catheters is supplied by Britannia Pharmaceuticals Ltd, 7-11 High Street, Reigate, Surrey RH2 9RR. These tubes are quite difficult to pass, and if they cannot be obtained readily a standard Ryle's tube, which is usually well tolerated by the patient, should suffice.

The gastroenterologist's prescribing habits will be influenced by the prevalence of infective diseases of the gastrointestinal tract. Thus antiparasitic agents, antibiotics, antidiarrhoeals, and antiemetics are essential. Constipation is a common complaint despite bulky diets, and therefore a choice of simple aperients or local laxative medicines is useful. The choice of drug must be tempered by cost, by its effectiveness, and by patient compliance. This applies particularly to compounds such as $\mathrm{H}_{2}$ receptor antagonists, steroids, and antispasmodics. Patients who may be expected to remain on long term treatment cannot necessarily either obtain or afford this. Under such circumstances surgery may have to be performed as a realistic alternative to long term drug treatment. The demand for medicine or tablets is often great; many patients attending the outpatient clinic will not be satisfied unless they are provided with tangible evidence of illness and treatment. Thus in my view a low cost placebo may be useful-either a Western proprietary medicine or one based on a traditional medicine.

The merit of giving hepatitis $B$ vaccine is a wide issue but is one in which the gastroenterologist may get concerned, and he may be expected to advise the local health ministry before it embarks on an expensive vaccination programme. He may also have to advise on preventive measures-for example, how to organise a clean water supply, dispose of sewage, etc. Thus he may be expected to undertake tasks outside his normal skills, and stripped of ancillary services the gastroenterologist faces a number of challenges. To meet these there is nothing more effective than enthusiasm, flexibility, and the application of knowledge in an appropriate manner. After all, this costs little apart from commitment and a sense of purpose, and in turn it may be rewarded richly.

I thank Dr L Farrow and Dr D Burnett for help in the preparation of this paper, and Mrs C Surrey for typing the manuscript.

\section{References}

${ }^{1}$ Mitchell FL. Comparison between problems on instrumentation in developed and developing countries. First African and Mediterranean congress of clinical chemistry. Milan: Italian Society of Clinical Biochemistry, 1980:49-53.

2 Mitchell FL. Supply, maintenance and repair of health care laboratory equipment in developing countries. Clinical Chemistry newsletter; news from African, Mediterranean and Near East countries 1983;4 142-55.

${ }^{3}$ Cotton PB, Williams CB. Practical gastrointestinal endoscopy. Oxford: Blackwell, 1980. 